in land clearing, cat-tail scarifying and discing to place non-stocked lands back into production. W. H. Cummings reported the addition to the research staff of a plant physiologist, pathologist, entomologist, and a wildlife specialist and the building of laboratory and greenhouse facilities for research work.

5. MacMillan \& Bloedel Ltd., in addition to their forest soil-site research work is planting nursery grown seedlings throughout the year to evaluate the effects of time of planting on survival and growth.

6. The University of Washington has added to its forest soils curriculum requiring two courses in soils for forestry students; forest soils research projects are being continued.

7. The Bureau of Land Management forest soils inventory co-operative study with Oregon State College concluded its first year, reporting on soil-site correlations with land form and minor vegetation and means of pre-typing of land form and soil conditions from aerial photos.

8. Committee Chairman George Schroeder and Secretary Stan Gessel reported that most chapters of the forest soils manual had been received and urged that committee members review the manuscripts and present their comments and suggestions before fall.

Special guests who commented briefly on the forest soils committee program and visit were Angus MacBean of MacMillan \& Bloedel Limited, Dr. B. G. Griffith, University of British Columbia, George Brown, Forestry Branch, Ottawa, and Robert McKinny, Department of Agriculture.

\title{
GifT Truck To C.F.A.
}

The Canadian Forestry Association, Prairie Provinces Division in Edmonton, received a new Chevrolet sedan delivery truck from General Motors for use in conservation work.

Presentation of the truck was made by W. L. Webster, GM Zone Manager in Calgary. On hand to receive the gift were members of the Association's Alberta Board of Directors, Dr .O. S. Longman, H. G. Jensen, Deputy Minister of Lands and Forests and Fred Jenner.

\section{B.C. Foresters Register}

The Council of the Association of British Columbia Foresters announces that the following candidates have completed the requirements and are now registered to practice forestry under the provisions of the B.C. Foresters Act: Robert C. Sutton, B.C. Forest Service, Prince George, B.C.; Robert H. Ahrens, B.C. Forest Service, Victoria, B.C.; Peter M. Leahy, B.C. Forest Service, Victoria, B.C.; F. Agar Pike, C. D. Schultz Co. Ltd., Vancouver, B.C.; Ralph W. Robbins, B.C. Forest Service, Prince George, B.C.; Peter H. West, B.C. Forest Service, Victoria, B.C.; O. Archibald Kaulbeck, Columbia Cellulose Co. Ltd., Terrace, B.C.; David C. Holmes, MacMillan \& Bloedel Ltd., Deerholme, B.C.; Paul J. Klotz, Eagle Lakes Sawmills Ltd., Giscome, B.C.; William J. W. Flemming, Lumby Planing Mills Ltd., Lumby, B.C.; D. Neil Paterson, B.C. Forest Service, Victoria, B.C.; George R. Battarbee, B.C. Forest Service, Victoria, B.C.

F. M. KNAPP, Registrar 